\title{
Productivity of medicinal raw materials by different genotypes of Matricia chammomila $L$. is affected with pre-sowing radiation exposure of seeds
}

\author{
Daryna Sokolova ${ }^{\circledR}$,*, Alexandra Kravets ${ }^{\circledR 1}$, Vladyslav Zhuk ${ }^{(1}$, Volodymyr Sakada ${ }^{(1}$, \\ Ludmila Glushenko ${ }^{\circledR 2}$, Mykola Kuchuk ${ }^{(D 1}$
}

${ }^{1}$ Institute of cell biology and genetic engineering, National Academy of Sciences of Ukraine, Kyiv
${ }^{2}$ Experimental station of medicinal plants of the Institute of Agroecology and Nature Management, National
Academy of Agrarian Sciences of Ukraine, Lubny

\begin{abstract}
One of the key tasks of modern pharmacology is complete and diverse use of natural raw materials - microorganisms and plants. So, different approaches of metabolism redirection were applied. Studying of plant protective reactions indicated a possibility to use various stress factors for the metabolism reorientation. One of the most effective approaches is to use ionizing and UV-C exposure. Thus, there is a shift in metabolic processes towards the formation of secondary metabolism substances with antioxidant, anticancer, immunomodulatory and anti-inflammatory effects. Biotechnological use of radiation exposure is based on the systemicity of radiobiological reactions, including protective and adaptive reactions in non-exposed organs («abscopal effect») and even in non-exposed organisms that are found in the same environment as exposed ones («by stander effect»). The products synthesized in these structures are some medicine materials and directly used by human. Radiation exposure affects developing, blocking of primary and secondary metabolism, so must be improved the selection of varieties with initial high productivity of medicinal raw materials, the choice of exposure and optimal doses inducing an increasing yield of the target metabolite and do not reduce the yield of medicinal raw materials. Effect of UV-C and X-ray pre-sowing exposure of seeds to the productivity of inflorescence formation of eight genotypes of Matricia chammomila L. was studied. There were indicated genotypes with increasing yield of inflorescence only under one or two exposure types and the variety with stimulation of flowering under UV-C exposure and absence of the marker under X-ray one.
\end{abstract}

\section{ARTICLE HISTORY}

Received: Mar 02, 2021

Revised: May 01, 2021

Accepted: May 11, 2021

\section{KEYWORDS}

pre-sowing radiation exposure,

Secondary metabolism, UV-C exposure,

$\mathrm{X}$-ray exposure, medicinal raw matherial

\section{INTRODUCTION}

With the increasing use of plants in official medicine, the variety of approaches to obtain more medicinal substances from the natural raw material expands (García-Granados et al., 2019; DellaPenna, 2001). Along with the search for new species with healing properties and the derivation of more productive varieties, metabolism redirection is used to increase the productivity of the substances necessary for practice (Dmytriev et al., 2018).

\footnotetext{
*CONTACT: Daryna Sokolova $\bowtie$ dasokolova88@gmail.com
} engineering, National Academy of Sciences of Ukraine, Kyiv 
One of the effective approaches is the application of both ionizing and non-ionizing radiation exposure (Klein et al., 2018; Jan et al., 2012; Alothman et al., 2009; Vardhan, \& Shukla, 2017; Nocchi et al., 2020). It was shown metabolic shift toward the formation of secondary metabolites, mostly radioprotectors, having antioxidant, anticancer, immunomodulatory, and anti-inflammatory effects under acute and chronic radiation exposure (Dai, \& Mumper, 2010; Kaur, \& Mondal, 2014; Unuofin, \& Lebelo, 2020; Pisoschi et al., 2016).

The development of any biotechnology inevitably faces some key issues, the solution of which should determine the reproducibility of the results. Under radiation exposure variability and plasticity of living things are found through all levels of their organization not limited to rearrangement only one metabolic direction, necessary for the practice. Reaction to the exposure covers the processes of growth and development, various blocks of primary and secondary metabolism, significantly changing their dynamic characteristics (Dmytriev et al., 2018; Jan et al., 2012). Thus, the development of technology to increase medicinal raw material under various radiation exposure types, in practice have to include:

a) Selection of varieties with high and stable productivity of medicinal raw material;

b) Choosing both type of radiation exposure and estimation of dose curves; an indication of optimal doses that do not decrease the yield of medicinal material and induce a higher level of the target metabolite;

c) Assessment of time coincidence of the yield of both pharmaceutical raw material and required metabolite with the total effect of the exposure.

The paper presents the results of studying both plant growth and development processes of different genotypes of chamomile, including the yield of crop formation of pharmaceutically significant raw materials under two types of radiation exposure: $\mathrm{UV}$ - $\mathrm{C}$ and $\mathrm{X}$-ray.

\section{MATERIAL and METHODS}

Chamomile is a wide-spread, long-day plant. It is a mesophyte, used in different countries in pharmacology and cosmetology during the treatment of inflammatory processes with various etiologies. The inflorescences of the plant are medicinal raw material (Matricaria chamomilla, 2021). Chamomile is a convenient experimental object.

The research was done using 8 genotypes of Matricaria chamomilla. 6 certified varieties of different origin were used: 1 - generative generation of the mutant Perlyna Lisostepu (treated with herbicide RaudAr in concentration 10); 2 - variety Kvedlinburg (Germany); 3 - variety Goral (Slovenia); 4 - variety Azulena (Russia); 5 - variety Zlatyi lan (Poland); 6 - variety Perlyna lisostepu (Ukraine). Non-varietal material, in fact, edaphic ecotypes, were included in the study: 7 - from manufacturer Gold Garden (Ukraine) further - ecotype Gold Garden; 8 from manufacturer Seed era (Ukraine) further - ecotype Seed era. The experiment was repeated three times.

Dry seeds were exposed with dose $10 \mathrm{~Gy}$, dose rate $1.42 \times 10^{-2} \mathrm{~Gy} / \mathrm{sec}$ using X-ray installation RUM-17 (Russia). UV-C exposure with dose $10 \mathrm{~kJ} / \mathrm{m}^{2}$, dose rate $3.4 \mathrm{~W} / \mathrm{m}^{2}$ was carried out using installation OBM-150 M (Ukraine) with two lamps Philips Special TUV $30 \mathrm{~W}$ (the Netherlands) maximum radiation under wavelength of $253.7 \mathrm{~nm}$.

Determination of pre-sowing exposure dose of dry seeds was based on wide-known effects in the field of "small" doses that lead to the stimulation effect of growth processes in parallel with DNA damage. According to the research, the optimal dose range for pre-sowing X-ray exposure of chamomile seeds was 5-10 Gy. The results were assigned with the patent (Shylina et al., 2018). 
The choice of UV-C exposure dose was based on both previous research of the exposure effects equivalent to chromosome aberration yield as a marker of low-intense radiation exposure with 10 Gy dose (Dmytriev et al., 2018) and dose curve of antioxidant yield.

The plants were grown in pots containing $1.5 \mathrm{~kg}$ of soil under the conditions of the vegetation experiment. According to the ecological characteristics of Matricaria chamomilla, sodpodzolic loamy soil was modeled mixing Polissky soil with sand in the ratio 1:2.

During the experiment, the physiological effects of ionizing and UV-C radiation exposure (germination, growth, a transition to flowering, flowering dynamics, the total yield of the target product) were studied. The inflorescences were collected at the stage of their full disclosure. The drying of raw materials was carried out in a dark room at a temperature of $25-27^{\circ} \mathrm{C}$. Statistical analysis of experimental findings - the mean value and variance value were calculated by traditional methods.

\section{RESULTS and DISCUSSION}

As shown in Figure 1, the stimulation of germination, in other words priming effect was not observed for all genotypes of the experiment. Priming effect, i.e. germination stimulation and synchronization with various stressors is intensively studied up-to-date. In addition to the phenomenon, there are unstable next stages of the production process, which brings the effect of priming with other hormesis effects (Kravets, \& Sokolova, 2017).

Hormesis effects during germination were observed for Goral variety, the mutant of Perlyna Lisostepu, ecotypes Golden Garden and Seed Era. They have maximum germination yield among variants exposed with UV-C. Along with high germination yield for non-varietal plants SeedEra, there was significant mortality yield during the transition to flowering under UV-C exposure. Both varieties Perlyna lisostepu and Zlatyi lan demonstrated germination stimulation under X-ray exposure. In general, germination dynamics for different chamomile varieties during the growing season had a multiphase nature. There were no common differences among the germination rate of exposed and control variants.

A significant effect of different radiation exposure types was shown during plant pass to flowering (Figure 2). There were distinct maximums of inflorescences under X-ray pre-sowing exposure for Kvedlinburg, Goral, and Azulena varieties. In contrast, other varieties did not show such reactions.

There is time congruence between start flowering time of both control and exposed with UV-C variants for mutant Perlyna lisostepu (Figure 2). However, the exposed demonstrated clearer maximum in contrast to the fairly "smooth" dynamics of inflorescences in control. There was a 10-day flowering delay for the variety under X-ray exposure. Also, the same delay with the maximum flowering index between 20th and 30th day was indicated for the Kvedlinburg variety. The maximum of the index for both UV-C and control variants appeared with a 10-day delay.

There was a clear maximum of the index for Goral variety with the same transition terms to flowering under X-ray exposure and a relatively "smooth" flowering formation dynamics for both control and UV-C exposed variants. All the variants of the Azulena variety characterized by the simultaneous transition to flowering. Moreover, flowering stimulation was indicated under X-ray exposure. 
Figure 1. Dynamics of germination of different chamomile genotypes. Confidence interval, $p=0.95$.
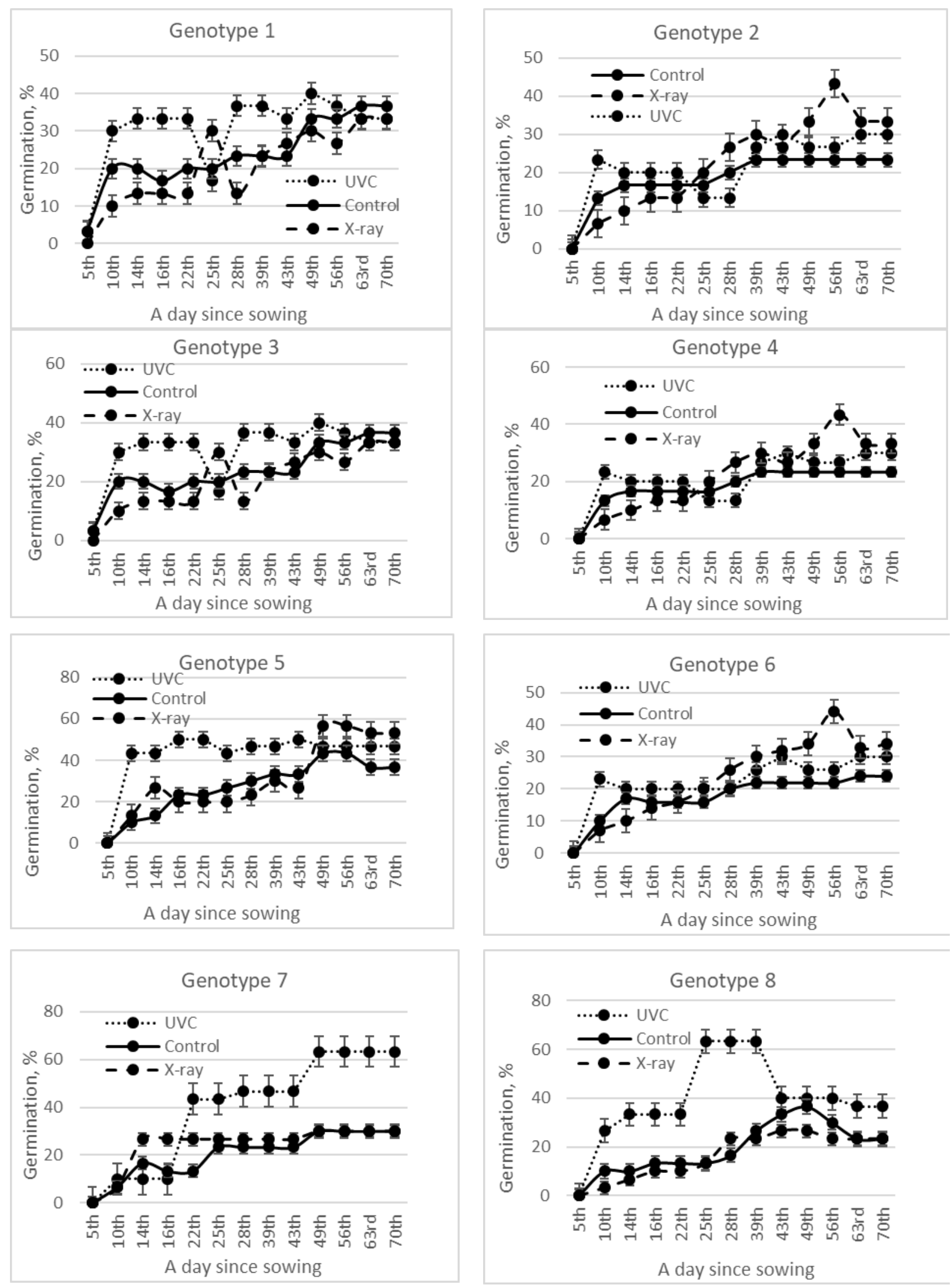
Figure 2. Dynamics of inflorescence formation by different chamomile genotypes. Confidence interval, $p=0.95$.
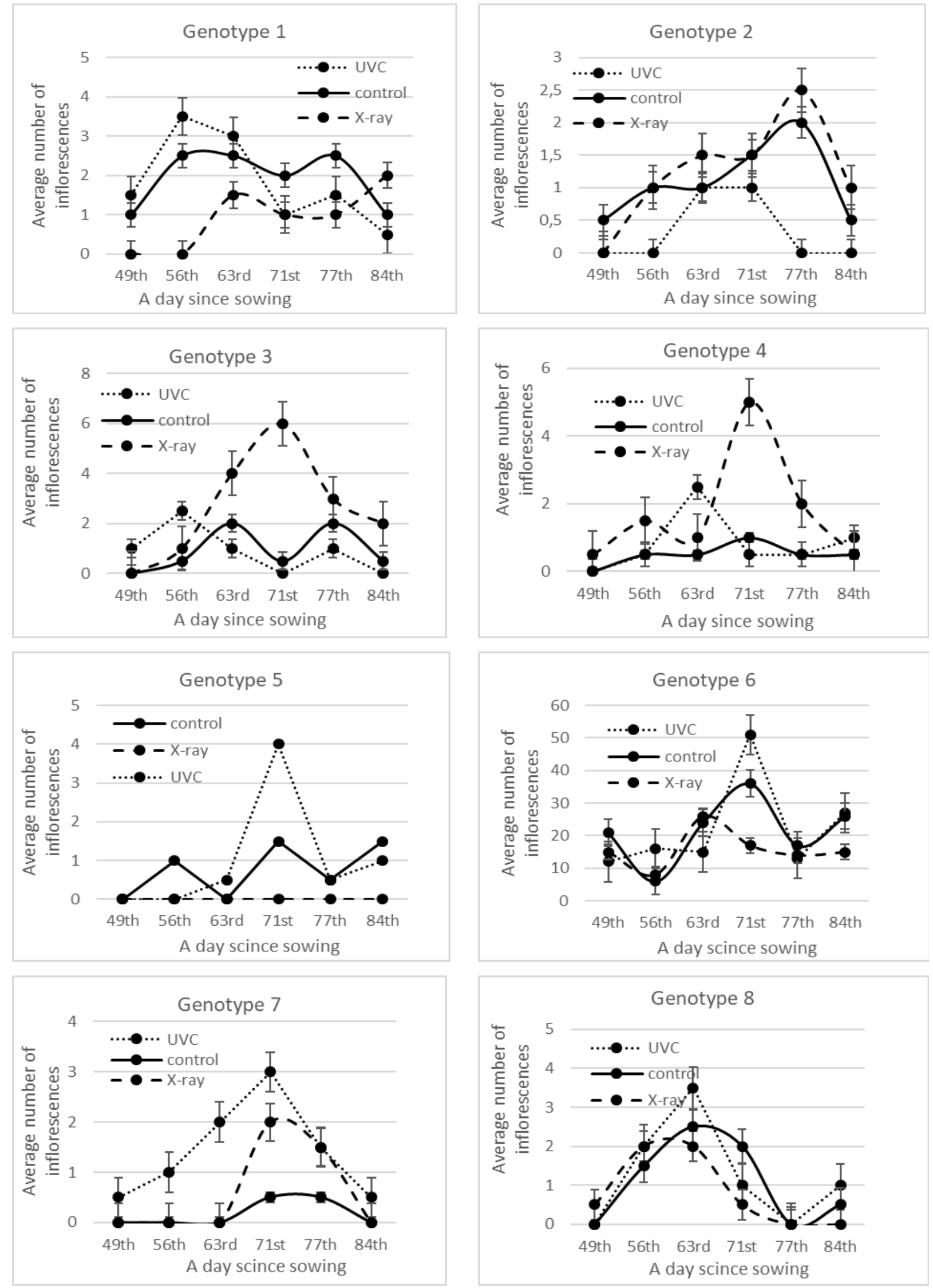
Figure 3. The total harvest of inflorescence collected during the season. Confidence interval, $p=0.95$.
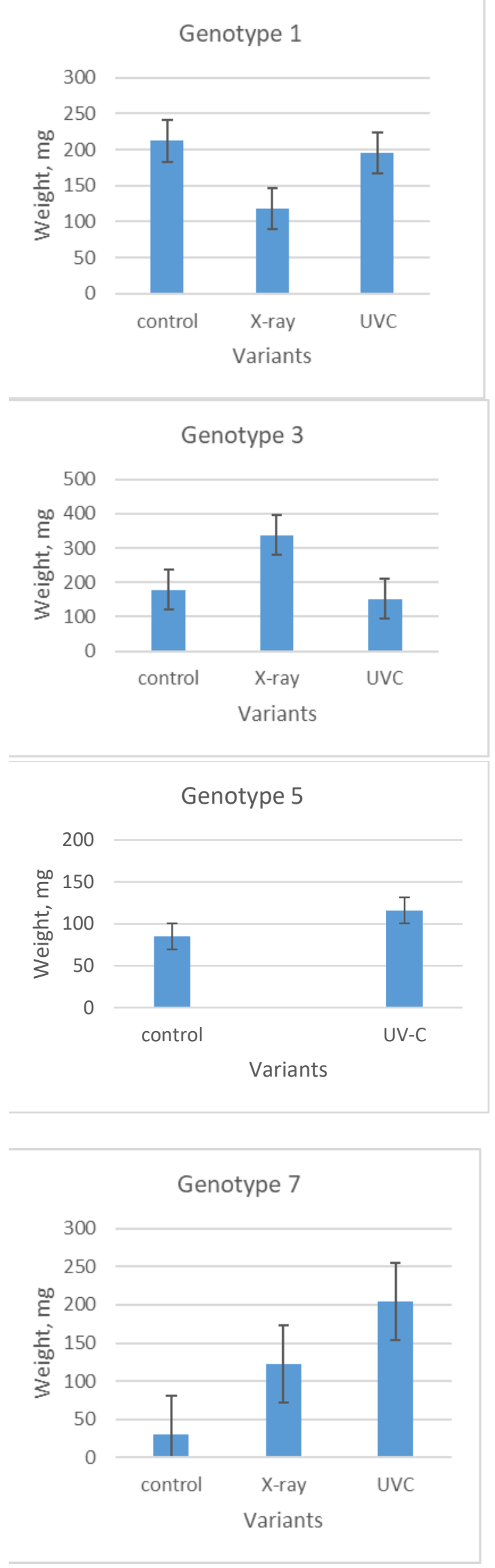
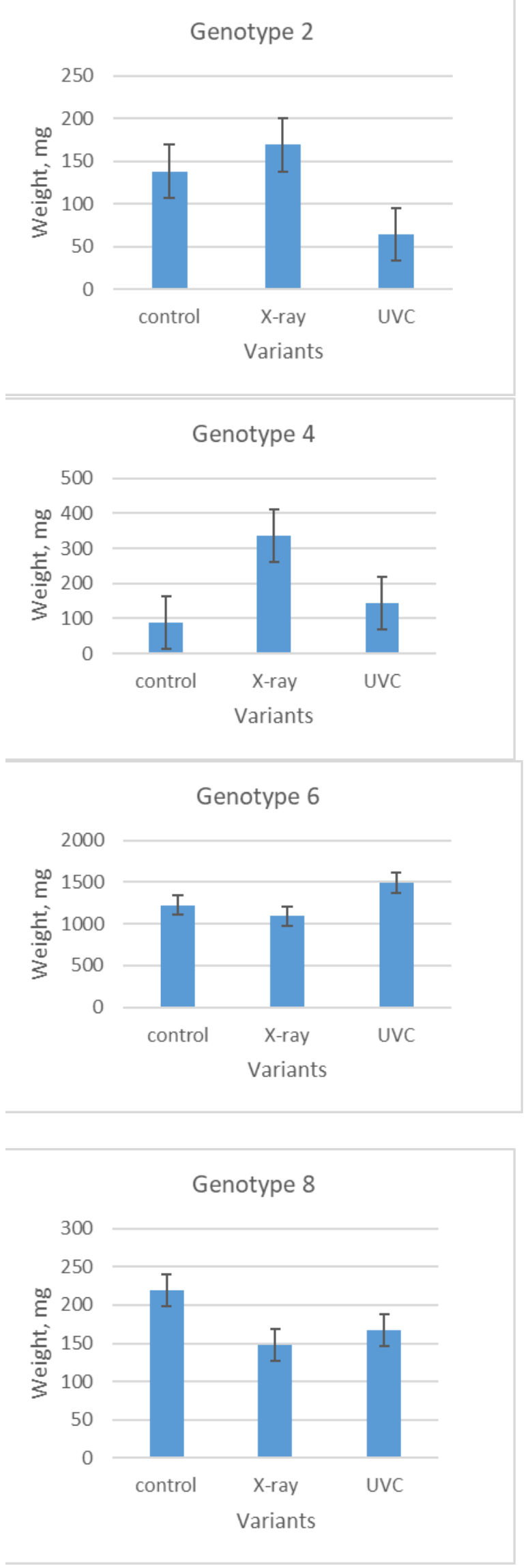
The total yield of pharmaceutical raw material, in this case - inflorescences, is an important technological marker. According to the research, all analysed genotypes differed with initial harvest yield. The highest yield of the inflorescences in control was indicated for Perlyna Lisostepu, the lowest one - for non-varietal ecotype Golden Garden.

Typically, start flowering time and its kinetics through different varieties exposed with various types of radiation were distinct among each other and control.

Obtained data showed various effectiveness of two radiation exposure types through different genotypes. Major stimulation of inflorescence yield from the one plant under X-ray exposure was indicated for most varieties: Kvedlinburg, Goral, Azulene. Stimulation with presowing UV-C exposure of seeds was shown for both Perlyna Lisostepu (variety of Ukrainian selection) and Zlatyi Lan (variety of Poland selection). Eightfold increased harvest yield was indicated for non-varietal plants Golden Garden and mutant Perlyna Lisostepu.

Comparison of the effects of priming and increasing the target productivity indicates the possibility of both coincidence and divergence of these markers through the genotypes under different types of radiation exposure (Figure 3). Stimulating both germination and harvest of the pharmaceutical products was indicated for Kvedlinburg and Asulena varieties under X-ray exposure. It was shown minor germination hormeziz effect and major stimulation of medicinal raw materials' formation for Perlyna Lisostepu variety under UV-C exposure. There was indicated germination stimulation under UV-C exposure and increasing yield of inflorescences' harvest under X-ray exposure for Goral variety. For Zlatiy lan variety the stimulation of germination under UV-C exposure coincided with the increasing yield of pharmaceutical raw material. However, these plants did not pass to flowering under X-ray exposure.

There is a difference between the primary "targeted" effects of UV-C and ionizing radiation exposure and, at the same time, the similarity of the effects of oxidative stress and the mechanisms of reparative processes under these two types of exposure (Dmytriev et al., 2018; Sinha, \& Hader, 2002). According to ecology and phytocoenology, it is known that increasing both the formation of generative organs and fertility, in general, is one of the forms of plant adaptive strategy (Rabotnov, 1983). Results concerning the difference through inflorescences' harvest of eight genotypes under the exposure indirectly indicated the formation otherness of the plant stress reactions under various types of radiation exposure. The diversity could include both primary damage processes associated with different compaction of plant chromatin of different genotypes and effectiveness of reparative, protective and antioxidant processes.

\section{CONCLUSION}

The results of studying the production process shown various reactions to a different type of radiation exposure through eight genotypes of chamomile. There were established genotypes in which increasing yield of inflorescence appeared only under one type of radiation exposure, variety in which stimulation of inflorescence yield was shown under two types of exposure and variety where flowering stimulation appeared under UV-C exposure and was absent under Xray exposure. The results indicating the difference in the yield of inflorescences of different genotypes under UV-C and X-ray exposure point to a difference through the formation of plant stress reactions at the organismal level.

Considering the applied focus of the study and the complexity of the plant organism's stress metabolic response, including different efficiency of enzymatic and non-enzymatic antioxidant systems, the next step in research aimed at increasing pharmaceutically important substances is to study the production of low molecular weight antioxidants as markers of stimulation of secondary metabolism. 


\section{Acknowledgments}

This work was supported by funding Scientific Investigative Projects NAS of Ukraine by project 1230/3"Studying the effect of biotic and abiotic stress factor exposure to the accumulation of secondary metabolites and recombinant compounds in genetically modified and native plant systems".

\section{Declaration of Conflicting Interests and Ethics}

The authors declare no conflict of interest. This research study complies with research and publishing ethics. The scientific and legal responsibility for manuscripts published in IJSM belongs to the authors.

\section{Authorship Contribution Statement}

Daryna Sokolova: Investigation, Methodology, Visualization, Software, Formal Analysis and Writing original draft. Alexandra Kravets: Investigation, Methodology, Visualization, Supervision, Validation and Writing original draft. Vladyslav Zhuk: Investigation, Methodology, Visualization, Software, Formal Analysis. Volodymyr Sakada: Methodology. Ludmila Glushenko: Resources. Mykola Kuchuk: Supervision.

Orcid

Daryna Sokolova (i) https://orcid.org/0000-0002-4540-0177
Alexandra Kravets (iD https://orcid.org/0000-0002-4979-5022
Vladyslav Zhuk (iD https://orcid.org/0000-0003-1966-7537
Volodymyr Sakada (i) https://orcid.org/0000-0002-9142-3660
Ludmila Glushenko (iD https://orcid.org/0000-0003-2329-5537
Mykola Kuchuk (D) https://orcid.org/0000-0001-7365-7474

\section{REFERENCES}

Alothman, M., Bhat, R., \& Karim, A. A. (2009). Effects of radiation processing on phytochemicals and antioxidants in plant produce. Trends in Food Science \& Technology, 20(5), 201-212. https://doi.org/10.1016/j.tifs.2009.02.003

Dai, J., \& Mumper, R. J. (2010). Plant Phenolics: Extraction, Analysis and Their Antioxidant and Anticancer Properties. Molecules, 15(10), 7313-7352. https://doi.org/10.3390/molecule $\underline{\mathrm{s} 15107313}$

DellaPenna, D. 2001. Plant Metabolic Engineering. Plant Physiology, 125(1), 160-163. https://doi.org/10.1104/pp.125.1.160

Dmytriev, O., Kravets, O., Rashydov, N., Bubryak, I., Guscha, M., Danchenko, M., Sokolova, D., Shylina, Yu., Berezhna, V., Bubryak, O., Dyachenko, A., Kryvohyzha, M., Lytvynov, S., Nesterenko, O., \& Sakada, V. (2018). Epigenetic factors of plant adaptation (O. Kravets \& Yu. Shylina Ed.). Kyiv, Ukraine: Palyvoda.

García-Granados, R., Lerma-Escalera, J.A., \& Morones-Ramírez, J.R. (2019). Metabolic Engineering and Synthetic Biology: Synergies, Future, and Challenges. Frontiers in Bioengineering and Biotechnology, 7, 36-38. https://doi.org/10.3389/fbioe.2019.00036

Hassan, W., Noreen, H., Rehman, Sh., Gul, Sh., Kamal, M. A., Kamdem, J. P., Zaman, B., \& da Rocha, J. B. T. (2017). Oxidative Stress and Antioxidant Potential of One Hundred Medicinal Plants. Current Topics in Medicinal Chemistry, 17(12), 36. https://doi.org/10.21 74/1568026617666170102125648

Jan, S., Parween, T., Siddiqi, T. O., \& Mahmooduzzafar. (2012). Effect of gamma radiation on morphological, biochemical, and physiological aspects of plants and plant products. Environmental Reviews, 20(1), 17-39. https://doi.org/10.1139/a11-021 
Kaur, S., \& Mondal, P. (2014). Study of total phenolic and flavonoid content, antioxidant activity and antimicrobial properties of medicinal plants. J Microbiol Exp., 1(1), 23-28. https://doi.org/10.15406/jmen.2014.01.00005

Klein, F. R. S., Reis, A., Kleinowski, A. M., Telles, R. T., Amarante, L. do, Peters, J. A., \& Braga, E. J. B. (2018). UV-B radiation as an elicitor of secondary metabolite production in plants of the genus Alternanthera. Acta Botanica Brasilica, 32(4), 615-623. https://doi.org/10.1590/0102-33062018abb0120

Kravets, A., \& Sokolova, D. (2017). Epigenetic mechanisms regulating seeds germination rate. Cytology and Genetics, 51(5), 346-351. https://doi.org/10.3103/S0095452717050048

Matricaria chamomilla. In Wikipedia, The Free Encyclopedia. Available online: https://en.wikipedia.org/w/index.php?title=Matricaria_chamomilla\&oldid $=1005657827$ (ac cesed on February 9, 2021)

Nocchi, N., Duarte, H. M., Pereira, R. C., Konno, T. U. P., \& Soares, A. R. (2020). Effects of UV-B radiation on secondary metabolite production, antioxidant activity, photosynthesis and herbivory interactions in Nymphoides humboldtiana (Menyanthaceae). Journal of Photochemistry and Photobiology B: Biology, 112021. https://doi.org/10.1016/j.jphotobiol. 2020.112021

Pisoschi, A. M., Pop, A., Cimpeanu, C., \& Predoi, G. (2016). Antioxidant Capacity Determination in Plants and Plant-Derived Products: A Review. Oxidative Medicine and Cellular Longevity, 2016, 1-36. https://doi.org/10.1155/2016/9130976

Rabotnov, T. (1983) Phytocenology. Moskow, Russia: Publishing House of Moscow University.

Salehi, B., Azzini, E., Zucca, P., Varoni, E. M., Kumar, N. V. A., Dini, L., Panzarini, E., Rajkovic, J., Fokou, P. V. T., Peluso, I., Mishra, A. P., Nigam, M., Rayess, Y. El., Beyrouthy, M. El., Setzer, W. N., Polito, L., Iriti, M., Sureda, A., Quetglas-Llabrés, M. M., Martorell, M., Martins, N., Sharifi-Rad, M., Estevinho, L. M., \& Sharifi-Rad, J. (2020). Plant-Derived Bioactives and Oxidative Stress-Related Disorders: A Key Trend towards Healthy Aging and Longevity Promotion. Appl. Sci., 10(3), 947. https://doi.org/10.3390/app10030947

Shylina, Y., Pchelovska, S., Lytvynov, S., Sokolova, D., Zhuk, V., Lystvan, K., Nesterenko, O., Salivon, A., \& Tonkal, L. (2018). Patent of Ukraine № 129749. Kyiv, Ukraine. Patent and trademark office. Retrieved from https://ukrpatent.org/uk/articles/bases2

Sinha, R., \& Hader, D. (2002). UV-induced DNA damage and repair: a review. Photochemical and Photobiological Sciences, 1(4), 225-236. https://doi.org/10.1039/b201230h

Unuofin, J. O., \& Lebelo, S. L. (2020). Antioxidant Effects and Mechanisms of Medicinal Plants and Their Bioactive Compounds for the Prevention and Treatment of Type 2 Diabetes: An Updated Review. Oxidative Medicine and Cellular Longevity, 2020, 1-36. https://doi.org/10.1155/2020/1356893

Vardhan, P. V., \& Shukla, L. I. (2017). Gamma irradiation of medicinally important plants and the enhancement of secondary metabolite production. International Journal of Radiation Biology, 93(9), 967-979. https://doi.org/10.1080/09553002.2017.1344788 